\title{
Evaluation of serum iron and ferritin in different treatment regimens for chronic hepatitis $\mathbf{C}$ virus
}

\author{
Fagr B. Bazeed ${ }^{1}$, Elsherbeny H. Elsayed ${ }^{2}$, Amani A. Abd El-Aziz ${ }^{2}$ \\ ${ }^{1}$ (Department of Biochemistry, College of Medicine/ Mansoura University, Egypt) \\ ${ }_{2}^{2}$ (Department of Chemistry, College of Science/ Port Said University, Egypt)
}

\begin{abstract}
This work aims to develop a biochemical study on the effect of both interferon containing treatment regimens and interferon free regimens on serum iron and serum ferritin in patients with chronic hepatitis $C$ and to evaluate the role of iron in the severity and course of disease. Blood samples from one hundred fifty patients aged from 25 to 57 years old were withdrawn; of them 30 blood samples were positive for HCV antibodies and negative for HCV RNA (control group I) and 120 blood samples were positive for HCV antibodies and positive for HCV RNA (diseased group II) which is subdivided into four groups according to the received treatment; interferon and ribavirin (group IIa), interferon, sofosbuvir and ribavirin (group IIb), sofosbuvir and ribavirin (group IIc) and herbal therapy (group IId). After treatment there was an extremely significant decrease in iron levels $(94 \pm 16.96 \mu \mathrm{g} / \mathrm{dL})$ in group IIa, while there was an extremely significant increase in iron levels after treatment in group IIb and group IIc (160.4 $\pm 37.53 \mu \mathrm{g} / \mathrm{dL}$ and $183.7 \pm 37.36 \mu \mathrm{g} / \mathrm{dL})$, respectively. Group IId showed a non significant decrease in iron levels after treatment $(150.5 \pm 21.35 \mu \mathrm{g} / \mathrm{dL})$. For ferritin levels, group IIa, group IIb and group IIc showed significant increase in serum ferritin levels after treatment (157.6 \pm 13.44 , $99.5 \pm 14.99$, and $96.63 \pm 15.22 \mathrm{ng} / \mathrm{mL}$ ), respectively. On the other hand, group IId showed a non significant increase in ferritin levels after treatment $(90.93 \pm 6.883 \mathrm{ng} / \mathrm{mL})$. It can be concluded that serum ferritin increases in $H C V$ patients treated with combined pegylated interferon--alfa (PEG-IFN)-ribavirin than the other treatment regimens. In addition, Serum iron decreases in HCV patients treated with combined PEG-IFNribavirin, while serum iron increases in sofosbuvir dual and trible therapy.
\end{abstract}

Keywords: Chronic hepatitis C, Serum iron, Serum ferritin, Pegylated interferon, Sofosbuvir, Herbal therapy.

\section{Introduction}

Hepatitis $\mathrm{C}$ virus (HCV) infection, which affects nearly $2 \%$ of the human population, is a major cause of liver disease worldwide. Following acute HCV infection, a chronic state is established in as many as $80 \%$ of infected individuals. Although many subjects carrying the virus remain asymptomatic, chronicity is often accompanied by altered liver function and progressive liver disease and culminates in cirrhosis or hepatocellular carcinoma in up to $20 \%$ of infected individuals [1]. Mild-to-moderate iron overload is a common finding among patients with chronic $\mathrm{HCV}$ infection; indeed, up to $30-40 \%$ of them may show increased serum transferrin-iron saturation and serum ferittin or increased hepatic iron concentration [2, 3]. Elevated iron indices have been correlated with a progression of the liver disease and a decreased response to antiviral therapy [4-9]. Excess iron increases the formation of reactive oxygen species leading to lipid peroxidation, damage to protein and DNA, and thereby to cell membranes and genomic damage. Reactive oxygen species, which include hydroxyl radicals, may cause hepatic stellate cell activation and proliferation and upregulate synthesis of smooth muscle actin and collagen, thus contributing to hepatic fibrogenesis [10-12]. Iron deposition in hepatocytes enhances HCV replication, thus facilitating the viral infection in the liver [13]. These hydroxyl radicals are known to generate promutagenic bases, such as 8-hydroxy-2'-deoxyguanosine (8-OHdG), which have been implicated in spontaneous DNA mutagenesis and carcinogenesis [14]. Therefore, there is need to configurate the distribution of iron and ferritin levels in patients with chronic HCV. This is what this study aims to achieve for Egyptian HCV patients. The study also aims to conduct a comparative study between the effects of the standard therapy for the treatment of chronic HCV infection pegylated interferon and ribavirin [15, 16], complementary alternative medicine (CAM) [17], and the newer NS5B RNA polymerase inhibitor Sofosbuvir [18] on serum iron and serum ferritin of $\mathrm{HCV}$ patients.

\section{Materials and methods}

One hundred and fifty (150) naïve HCV out patients aged from 25 to 57 years attending the medical outpatient clinics of General Authority of Health Insurance hospital, Mansoura, Egypt, participated in the study. These were divided into a group of 30 patients who were positive for HCV antibodies and negative for HCV RNA (control group I) and a group of 120 patients who were positive for HCV antibodies and positive for HCV RNA (diseased group II). The diseased group is subdivided into four groups according to the received treatment; 
interferon and ribavirin group for 48 weeks (group IIa $n=30$ ), sofosbuvir, interferon and ribavirin group for 12 weeks (group IIb $n=30$ ), sofosbuvir and ribavirin group for 24 weeks (group IIc $n=30$ ) and finally herbal group for 24 weeks (group IId n=30).

The enzyme-linked immunosorbent assay (ELISA) commercial kit (Micro LISA HCV Ab; Amgenix, USA) was used for detecting anti- HCV Abs by Voller technique [19]. Serum HCV viral RNA was extracted using the QIAamp viral RNA mini kit (Qiagen, CA, USA). The extract was subjected to a quantitative HCV viral evaluation by real-time PCR according to the procedures in the instruction manual of the artus ${ }^{\circledR} \mathrm{HCV}$ RG RT-PCR kit (Qiagen) performed on a Rotor gene 5 plex instrument (Qiagen). HCV genotyping was performed on HCV-RNA-positive samples, using the VERSANT HCV LiPA 2.0 (Inno-Lipa HCV; Innogenetics, Ghent, Belgium). However, HCV genotype 4 was the common genotype in the tested cases. Blood samples were obtained at recruitment (non-fasting) and measured at routine hospital laboratories for the following parameters: s.iron (Fe), serum ferritin (s.ferritin). Serum iron was measured by Garcic method [20] while Serum ferritin was determined by chemiluminescence assay using Elecsys immunoassay analyzers [21].

(Group IIa) patients were prescribed subcutaneous pegylated IFN- $\alpha 2 a$ (Reiferon Retard Vials, MINAPHARM, 10th of Ramadan, Egypt) $160 \mu \mathrm{g}$ once weekly and oral ribavirin (MINAPHARM) 1000 or 1200 $\mathrm{mg}$ daily (1000 $\mathrm{mg}$ for those less than $75 \mathrm{~kg}$ body weight and $1200 \mathrm{mg}$ for those more than $75 \mathrm{~kg}$ ) for 48 weeks, patients in (group IIb) received subcutaneous pegylated IFN- $\alpha 2 \mathrm{a}$, sofosbuvir (Gratisovir $400 \mathrm{mg}$ tablet, PHARCO, Alexandria, Egypt) and oral ribavirin for 12 weeks, (group IIc) patients received sofosbuvir $400 \mathrm{mg}$ and ribavirin for 24 weeks, additionally patients in (group IId) received the herbal mixture (Bee venom previously isolated from honeybee (Apis Mellifera), by intradermal injection according to a schedule of a starting dose of $10 \mu \mathrm{g}$ on the $1^{\text {st }}$ day, $40 \mu \mathrm{g}$ on the $3^{\text {rd }}$ day, $60 \mu \mathrm{g}$ on the $5^{\text {th }}$ day and finally a maintenance dose of $100 \mu \mathrm{g}$ weekly, $300 \mathrm{mg}$ of boswellia serrata taken orally in capsule form 3 times a day, and Yi zhu decoction formulation taken orally as pills by taking $500 \mathrm{mg}$ of pills 3 times daily for 24 weeks). Sofosbuvir taken orally, once daily with or without food. Ribavirin taken with food.

Analyses of data were done with GraphPad Prism version5 statistical programme. Quantitative data were presented as mean \pm standard deviation (SD), and a p-value $<0.05$ was considered significant. Pearson's correlation coefficient was used to examine the presence of any correlation between serum iron and ferritin.

\subsection{Pre-treatment serum iron and ferritin}

\section{Results}

Patients in group IIa, group IIc and group IId showed an extremely significant higher serum iron (mean: 135.00, 147.00 and $155.00 \mu \mathrm{g} / \mathrm{dL}$ respectively; $\mathrm{P}<0.0001)$ than the normal control group (mean: 107.00 $\mu \mathrm{g} / \mathrm{dL}$ ). Patients in group IIb showed a non significant increase (mean: $120.00 \mu \mathrm{g} / \mathrm{dL} ; \mathrm{P}>0.05$ ) compared with the normal control group. Serum ferritin in all diseased groups (group IIa, group IIb, group IIc, and group IId) showed an extremely significant decrease (mean: 80.00, 75.00, 85.00, and $82.00 \mathrm{ng} / \mathrm{mL}$ respectively; $\mathrm{P}<0.0001$ ) than the normal control group (mean: $107.2 \mathrm{ng} / \mathrm{mL}$ ). Pretreatment iron and ferritin levels of all the studied groups are listed in (table 1).

\subsection{Post-treatment serum iron and ferritin}

Table 2 shows the post treatment levels of serum iron and ferritin in all groups. Iron levels showed an extremely significant decrease in group IIa (mean: $94.00 \mu \mathrm{g} / \mathrm{dL} ; \mathrm{P}<0.0001$ ) after treatment, While there was an extremely significant increase in iron levels after treatment in group IIb and group IIc (mean: 160.4 and $183.7 \mu \mathrm{g} / \mathrm{dL}$ respectively; $\mathrm{P}<0.0001)$. In addition, group IId showed a non significant decrease in iron levels after treatment (mean: $150.5 \mu \mathrm{g} / \mathrm{dL} ; \mathrm{P}>0.05$ ). Ferritin levels showed an extremely significant increase after treatment in group IIa (mean $157.6 \pm 13.44 \mathrm{ng} / \mathrm{mL}, \mathrm{P}<0.0001$ ). While, there was a very significant increase in serum ferritin levels after treatment in group IIb (mean $99.5 \pm 14.99 \mathrm{ng} / \mathrm{mL}, \mathrm{P}<0.001$ ) and a significant increase in group IIc (mean $96.63 \pm 15.22 \mathrm{ng} / \mathrm{mL}, \mathrm{P}<0.05$ ). On the other hand, group IId showed a non significant increase in ferritin levels after treatment (mean $90.93 \pm 6.883 \mathrm{ng} / \mathrm{mL}, \mathrm{P}>0.05$ ). The $\%$ change in serum iron and ferritin levels with treatment is illustrated in fig.1 (a and b). 


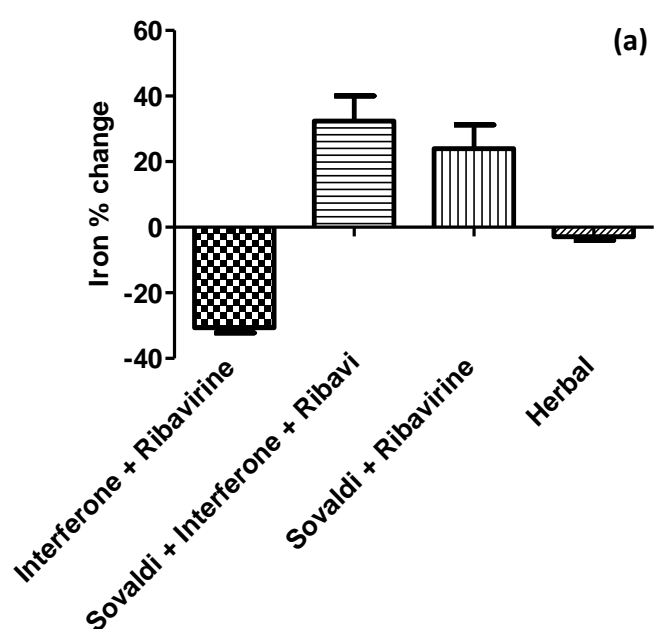

(a)
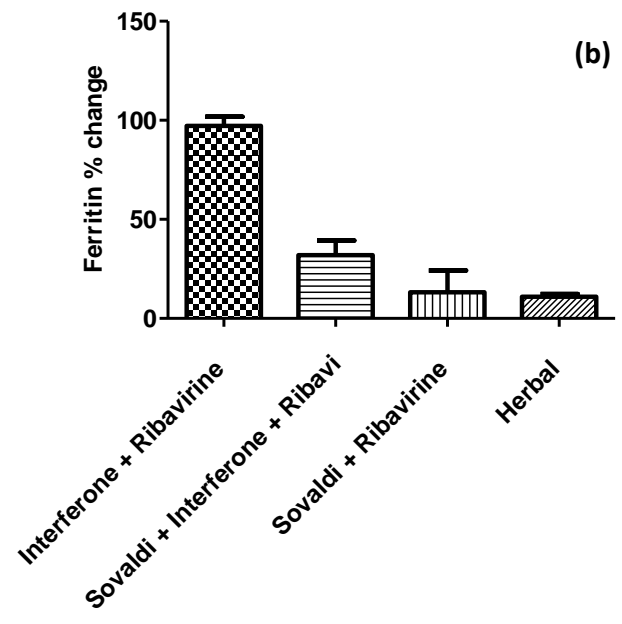

Figure 1. The \% change of the evaluated serum iron and ferritin with treatment in all the studied groups. (a) Serum iron \% change with treatment. (b) Serum ferritin \% change with treatment.

Table 1. Pretreatment serum iron and ferritin levels of the diseased groups compared to the control group $(n=30)$

\begin{tabular}{|c|c|c|c|c|}
\hline \multirow[t]{2}{*}{ Groups } & \multicolumn{4}{|c|}{ Biomarkers } \\
\hline & Serum iron $(\mu \mathrm{g} / \mathrm{dL})$ & P-value & Serum ferritin (ng/mL) & P-value \\
\hline Group I** & \multicolumn{2}{|l|}{$107.2 \pm 26.62$} & \multicolumn{2}{|l|}{$107.2 \pm 26.62$} \\
\hline Group IIa** & $135 \pm 21.53 *$ & $\mathrm{p}<0.0001$ & $80 \pm 7.178^{*}$ & $\mathrm{p}<0.0001$ \\
\hline Group IIb** & $120 \pm 21.53$ & ns & $75 \pm 7.178^{*}$ & $\mathrm{p}<0.0001$ \\
\hline Group IIc** & $147 \pm 21.53 *$ & $\mathrm{p}<0.0001$ & $85 \pm 7.178^{*}$ & $\mathrm{p}<0.0001$ \\
\hline Group IId** & $155 \pm 22.36^{*}$ & $\mathrm{p}<0.0001$ & $82.03 \pm 6.64 *$ & $\mathrm{p}<0.0001$ \\
\hline
\end{tabular}

* Extremely significant different from control group at $\mathrm{P}<0.0001$.

**Group I, control group; Group IIa, diseased group treated with IFN- $\alpha 2$ a and ribavirin; Group IIb, diseased group treated with IFN- $\alpha 2 \mathrm{a}$, sofosbuvir and ribavirin; Group IIc, diseased group treated with sofosbuvir and ribavirin; Group IId; diseased group treated with herbal therapy.

\subsection{Correlation between serum iron and serum ferritin}

Simple linear regression analysis showed that serum iron levels in group IIb and group IIc (sofosbuvir trible and dual therapy) were significantly positive correlated with serum ferritin $(\mathrm{r}=0.607, \mathrm{P}<0.0001 ; \mathrm{r}=0.343$, $\mathrm{p}=0.007$ respectively) while; a significant negative correlation was observed between serum iron and ferritin in group IIa and group IId ( $\mathrm{r}=-0.487, \mathrm{p}<0.0001 ; \mathrm{r}=-0.289, \mathrm{p}=0.025$ respectively).

Table 2. Post treatment levels of serum iron and ferritin compared to pre treatment levels $(n=30)$

\begin{tabular}{|c|c|c|c|c|c|c|}
\hline \multirow[t]{3}{*}{ Groups } & \multicolumn{6}{|c|}{ Biomarkers } \\
\hline & \multicolumn{3}{|c|}{ Iron $(\mu \mathrm{g} / \mathrm{dL})$} & \multicolumn{3}{|c|}{ Ferritin (ng/mL) } \\
\hline & Pre-treatment & Post-treatment & P-value & Pre-treatment & Post-treatment & P-value \\
\hline Group IIa & $135 \pm 21.53$ & $94 \pm 16.96^{*}$ & $\mathrm{p}<0.0001$ & $80 \pm 7.178$ & $157.6 \pm 13.44^{*}$ & $\mathrm{p}<0.0001$ \\
\hline Group IIb & $120 \pm 21.53$ & $160.4 \pm 37.53^{*}$ & $p<0.0001$ & $75 \pm 7.178$ & $99.5 \pm 14.99 *$ & $p<0.0001$ \\
\hline Group IIc & $147 \pm 21.53$ & $183.7 \pm 37.36^{*}$ & $\mathrm{p}<0.0001$ & $85 \pm 7.178$ & $96.63 \pm 15.22 *$ & $p<0.05$ \\
\hline Group IId & $155 \pm 22.36$ & $150.5 \pm 21.35$ & ns & $82.03 \pm 6.641$ & $90.93 \pm 6.88$ & ns \\
\hline
\end{tabular}

* Extremely significant different from pre-treatment levels at $\mathrm{P}<0.0001$; significant different from pretreatment levels at $\mathrm{P}<0.05$.

Table 3. Pearson's correlation between serum iron \& serum ferritin levels in all the studied groups.

\begin{tabular}{|c|c|c|c|c|c|c|c|c|}
\hline \multirow[t]{2}{*}{ Parameter } & \multicolumn{2}{|c|}{ Group IIa } & \multicolumn{2}{|c|}{ Group IIb } & \multicolumn{2}{|c|}{ Group IIc } & \multicolumn{2}{|c|}{ Group IId } \\
\hline & $r$ & $P$-value & $r$ & $P$-value & $r$ & $P$-value & $r$ & $P$-value \\
\hline Iron \& ferritin & $-0.487 *$ & $<0.0001$ & $0.607^{*}$ & $<0.0001$ & $0.343^{*}$ & 0.007 & $-0.289 *$ & 0.025 \\
\hline
\end{tabular}

* Extremely significant correlation at $\mathrm{P}<0.0001$; very significant correlation at $\mathrm{p} \mathrm{P}<0.001$; significant correlation at $\mathrm{P}<0.05 \&$ non significant at $\mathrm{P}>0.05$. 


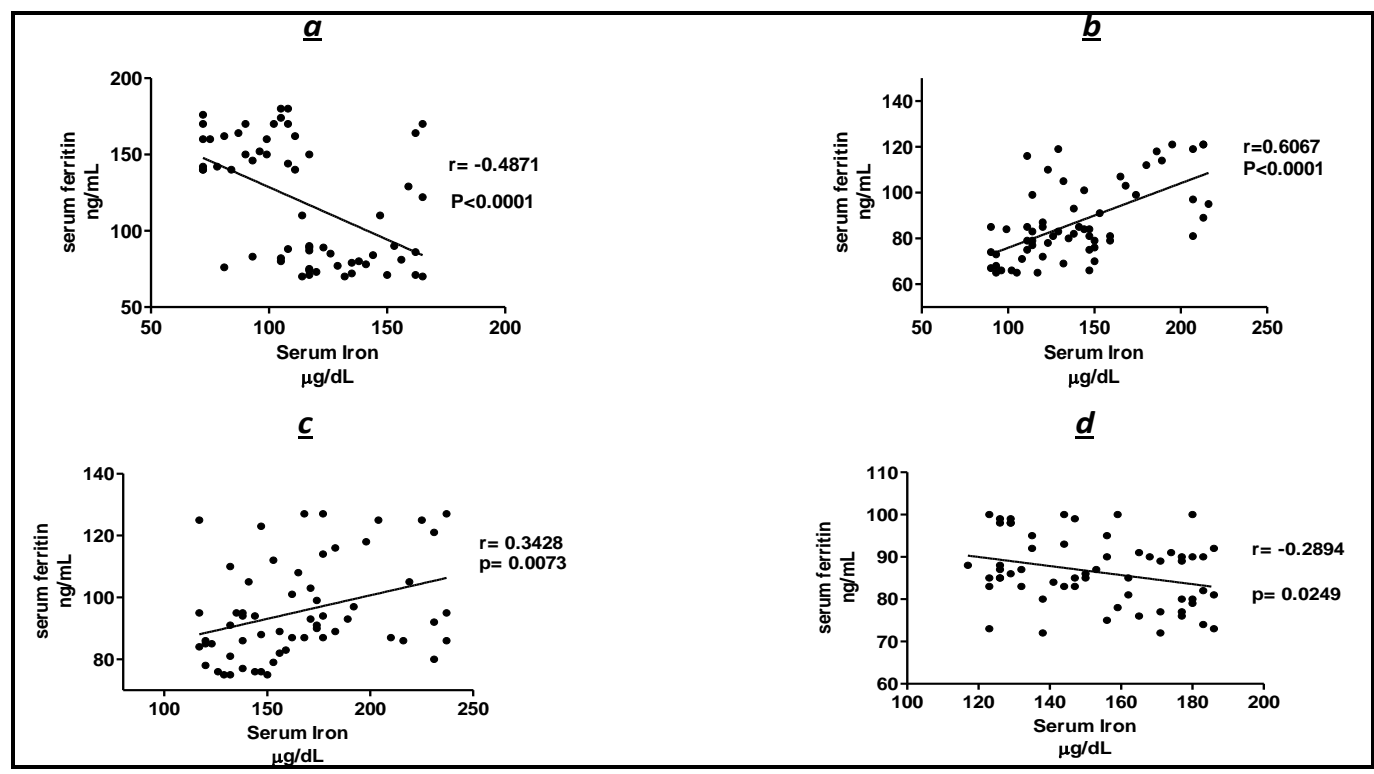

Figure 2. Correlations between serum iron and serum ferritin in all the studied groups. (a) Correlation between serum iron and serum ferritin in group IIa. (b) Correlation between serum iron and serum ferritin in group IIb. (c) Correlation between serum iron and serum ferritin in group IIc. (d) Correlation between serum iron and serum ferritin in group IId.

\section{Discussion}

$\mathrm{HCV}$ is a human hepatotropic virus of the family Flaviviridae with positive-strand RNA. In most cases, it establishes a lifelong chronic infection [22]. Elevated iron parameters and mild iron overload are common in the liver of patients with chronic hepatitis $\mathrm{C}$. It has been suggested that serum iron and serum ferritin might be correlated with liver inflammation and serum markers of fibrogenesis [23, 24]. Moreover, some studies suggest that iron excess in the liver may favor the persistence of viral infection [25, 26]. A combination of pegylated interferon- $\alpha$ (peg-IFN) and ribavirin was used to treat $\mathrm{CHC}$ with disappointing viral eradication rates. Recently, there has been an improvement in SVR rates with the development and approval of the HCV-specific directacting antiviral agents (DAAs) [27, 28]. In contrast to the non-specific antiviral activity of peg-IFN and ribavirin, DAAs are designed to inhibit viral proteins involved in the HCV life cycle. Sofosbuvir (SOF), a potent nucleotide nonstructural 5B polymerase inhibitor, in combination with RBV is approved for treatment of genotype 1, 2, 3, 4, 5 and 6 chronic HCV infection [29-31]. On the other hand, CAM is being used increasingly across the globe for many chronic diseases $[32,33]$. Some medicinal herbs might have therapeutic potential in CHC, or may alleviate side effects of conventional therapy [34]. Although sometimes thought by the public to be safer than conventional therapy, there are many reports about liver toxicity and other adverse events from some herbal products $[32,35]$. In this study the effect of antiviral treatment on serum iron and liver iron concentration assessed by serum ferritin was studied before and after treatment to evaluate further the role of iron on the pathogenesis of chronic hepatitis $\mathrm{C}$.

Regarding pre-treatment serum Iron and serum ferritin levels; there was a statistically significant difference between the base line levels of iron in all $\mathrm{CHC}$ patient groups and the normal control group except in group IIb which showed no significant difference in iron levels compared to the control group. The median of ferritin levels in all the patient groups showed a statistically significant decrease compared to the median of the control group. This indicates normal iron stores but rules out iron overload [36] where most naïve CHC have blood serum iron markers within the normal range. Some other authors $[24,37,38]$ found that cirrhotic persons had deviations from normal results while, patients with chronic hepatitis had normal serum iron parameters [39] and those patients are more expected to achieve SVR after treatment [40].

The results concerning iron and ferritin levels in all patient groups after the four treatment regimens included in our study showed that; in case of (group IIa) there was an extremely significant decrease in serum iron at the end of treatment. It is a common side effect of long duration of interferon therapy where anemia is a common complication occurring in up to $30 \%$ of subjects. PEG-IFN-a suppresses HCV production by augmenting the innate antiviral immune response. Recent data showed that interferon alpha may increase hepcidin (the iron regulatory hormone) production, resulting in impaired iron availability for production of red blood cells. In addition, other studies have reported that a single dose of PEG-IFN-a/RBV resulted in a significant increase in serum hepcidin, peaking at 12 hours, coinciding with a 50\% reduction in serum iron and transferrin saturation over the 24-hour period [41]. However, serum ferritin levels in the same group showed an 
extremely significant increase after treatment; Interferon alpha is one of the stimulants of SF. Previous studies examined differences in SF levels during peg interferon (PEG-IFN) plus ribavirin combination therapy; they found that patients who achieved SVR had lower baseline ferritin levels. It was observed that SF levels increased dramatically in both the SVR and non-SVR groups after starting therapy, remained high until the end of the treatment period [40]. Our results are in agreement with these findings. Other authors pointed to a central role for the cytokine network in the modulation of iron metabolism in the acute-phase response and anemia of chronic disease which characterized by hypoferraemia associated with an increased ferritin synthesis. TNF, possibly via induction of IL-6, and IFN-gamma induce hypoferraemia, which may in part result from a decrease in tissue iron release based on a primary stimulation of ferritin synthesis [42].

In case of (group IIb) treated with Sofosbuvir, ribavirin and pegylated interferon for 12 weeks, we observed a significant increase in serum iron level after treatment but it did not reach the upper limit of normal; this may be due to the shorter duration of interferon therapy compared to the old regimen of 48 weeks, so little hepcidin (the iron regulatory hormone) production resulting in little reduction in serum iron. Also, sofosbuvir is an oral direct acting antiviral agent inhibits the RNA polymerase that the hepatitis $\mathrm{C}$ virus uses to replicate its RNA [43]. Its action does not depend on augmenting the innate antiviral immune response as interferon, so it has no effect on serum iron. Also, this increase in serum iron may be due to ribavirin induced hemolytic anemia that increases serum iron because red blood cells are being destroyed too quickly [44]; this action may be counteracted by hepcidin production in case of 48 weeks INF- ribavirin treatment. In case of (Group IIc) treated with sofosbuvir plus ribavirin for 24 weeks, serum iron level showed an extremely significant increase after treatment (high normal value) where it is an interferon free regimen so we avoided the common interferon side effect of reducing serum iron. Also, it was observed that the absorption of dietary iron is better during interferon free regimens. Additionally, the RBCs hemolytic side effect of ribavirin increasing serum iron. Ferritin levels in (group IIb) showed a moderate significant increase after treatment (less than group IIa) where shorter duration of interferon in (group IIb). While, (group IIc) showed a weak increase in ferritin levels after treatment; where absence of interferon in this group. This mild increase may be related to high serum iron level of this group which may increase stored iron in the liver expressed by ferritin. These results showed that sofosbuvir has no or little effect on ferritin where its action is directly on the virus.

By the analysis of (group IId) treated with the herbal therapy we found that there was no significant difference in serum iron and serum ferritin levels after treatment so we can say that herbal therapy has no effect on iron and ferritin. Previous studies evaluated complementary and alternative treatments and showed that herbal remedies may be able to lower viral load in humans with prolonged treatment but they have no effect on iron and ferritin levels [45].

Regarding the correlation studies; we observed a distinct pattern of changes in serum iron and serum ferritin concentrations during the four treatment regimens included in our study where, (PEG-IFN)-ribavirin treatment induce immune response assessed by an increase in serum ferritin levels and a decline in serum iron levels. So, we obtained a significant negative correlation between serum iron and serum ferritin during this treatment regimen while, direct acting antiviral agent regimens (both with and without interferon) exhibit an increase in serum iron with a moderate and weak significant increase in serum ferritin levels respectively. Consequently; we obtained a significant positive correlation between serum iron and serum ferritin in both group IIb and IIc. On the other hand, serum iron and ferritin levels showed no significant differences after herbal treatment; this explains the weak significant correlation between serum iron levels and serum ferritin in group IId. These findings may shed light to the relationship between HCV treatment and serum iron and ferritin concentrations.

\section{Conclusion}

This article provides a comparative study between interferon containing treatment regimens and interferon free regimens such as herbal therapy and sofosbuvir dual therapy; we can conclude that serum ferritin increases with higher levels in HCV patients treated with combined pegylated interferon--alfa (PEG-IFN)ribavirin for 48 weeks than those treated with interferon, sofosbuvir and ribavirin for 12 weeks. So, the duration of interferon treatment has an effect on serum ferritin levels. While interferon-free regimens including herbal therapy and sofosbuvir dual therapy; have little or no effect on serum ferritin levels. On the other hand, serum iron level decreases in HCV patients that treated with combined pegylated interferon--alfa (PEG-IFN)-ribavirin for 48 weeks and it is a common side effect of long duration of interferon therapy. While serum iron increases in sofosbuvir dual and trible therapies; this is because of better absorption of dietary iron in interferon free regimen and shorter duration of interferon therapy respectively. In addition serum iron level shows no change during the course of herbal treatment. This study may also shed light on how the changes in serum iron and ferritin levels in chronic hepatitis $\mathrm{C}$ patients may be related to $\mathrm{HCV}$ treatment. 


\section{References}

[1] Mustapha, O., et al., Genital ulceration associated with typhoid fever. Am J Obstet Gynecol, 2009. 200(5): p. e6-7.

[2] Bitar, M.A. and G.S. Dbaibo, Neonatal neck mass in identical twins: an unusual presentation. Am J Perinatol, 2005. 22(6): p. 311-5.

[3] Flaker, G.C., et al., Superiority of biphasic shocks in the defibrillation of dogs by epicardial patches and catheter electrodes. Am Heart J, 1989. 118(2): p. 288-91.

[4] Gion, T., et al., Perioperative change in albumin messenger RNA levels in patients with hepatocellular carcinoma. Hepatology, 1998. 28(6): p. 1663-8.

[5] Yoshiji, H., et al., Vascular endothelial growth factor tightly regulates in vivo development of murine hepatocellular carcinoma cells. Hepatology, 1998. 28(6): p. 1489-96.

[6] Takayama, T., et al., Early hepatocellular carcinoma as an entity with a high rate of surgical cure. Hepatology, 1998. 28(5): p. 12416.

[7] Sudan, D., et al., Without victory there is no survival: transarterial lipiodol chemoembolization and hepatocellular carcinoma. Hepatology, 1998. 28(1): p. 270-1.

[8] Yamaguchi, R., et al., Expression of vascular endothelial growth factor in human hepatocellular carcinoma. Hepatology, 1998. 28(1): p. 68-77.

[9] Atarashi, Y., et al., A novel human tumor necrosis factor alfa mutein, F4614, inhibits in vitro and in vivo growth of murine and human hepatoma: implication for immunotherapy of human hepatocellular carcinoma. Hepatology, 1998. 28(1): p. $57-67$.

[10] Okada, S., Transcatheter arterial embolization for advanced hepatocellular carcinoma: the controversy continues. Hepatology, 1998. 27(6): p. 1743-4.

[11] Bruix, J., et al., Transarterial embolization versus symptomatic treatment in patients with advanced hepatocellular carcinoma: results of a randomized, controlled trial in a single institution. Hepatology, 1998. 27(6): p. 1578-83.

[12] Llovet, J.M., et al., Liver transplantation for small hepatocellular carcinoma: the tumor-node-metastasis classification does not have prognostic power. Hepatology, 1998. 27(6): p. 1572-7.

[13] Ikeda, Y., et al., Prognosis of hepatocellular carcinoma with diabetes mellitus after hepatic resection. Hepatology, 1998. 27(6): p. $1567-71$.

[14] Mandishona, E., et al., Dietary iron overload as a risk factor for hepatocellular carcinoma in Black Africans. Hepatology, 1998. 27(6): p. 1563-6.

[15] Fried, M.W., et al., Peginterferon alfa-2a plus ribavirin for chronic hepatitis C virus infection. New England Journal of Medicine, 2002. 347(13): p. 975-982.

[16] Manns, M.P., et al., Peginterferon alfa-2b plus ribavirin compared with interferon alfa-2b plus ribavirin for initial treatment of chronic hepatitis C: a randomised trial. The Lancet, 2001. 358(9286): p. 958-965.

[17] Jacobs, B.P., et al., Milk thistle for the treatment of liver disease: a systematic review and meta-analysis. The American journal of medicine, 2002. 113(6): p. 506-515.

[18] Kattakuzhy, S., R. Levy, and S. Kottilil, Sofosbuvir for treatment of chronic hepatitis C. Hepatology international, 2015. 9(2): p. 161-173.

[19] Voller, A., The enzyme-linked immunosorbent assay (ELISA)(theory, technique and applications). La Ricerca in clinica e in laboratorio, 1977. 8(4): p. 289-298.

[20] Garcic, A., Highly Sensitive, Simple Determination of Serum Iron Using Chromazurol-B. Clinica Chimica Acta, 1979. 94(2): p. $115-119$.

[21] Lotz, J., G. Hafner, and W. Prellwitz, Reference study for ferritin assays. Clinical Laboratory, 1997. 43(11): p. 993-994.

[22] Lavanchy, D., Evolving epidemiology of hepatitis C virus. Clinical Microbiology and Infection, 2011. 17(2): p. 107-115.

[23] Pietrangelo, A., Iron, oxidative stress and liver fibrogenesis. Journal of hepatology, 1998. 28: p. 8-13.

[24] Casaril, M., et al., Role of iron load on fibrogenesis in chronic hepatitis C. Hepato-gastroenterology, 1999. 47(31): p. 220-225.

[25] Felton, C., et al., Serum iron levels and response to hepatitis B virus. Proceedings of the National Academy of Sciences, 1979. 76(5): p. 2438-2441.

[26] Lustbader, E.D., H. Hann, and B.S. Blumberg, Serum ferritin as a predictor of host response to hepatitis B virus infection. Science, 1983. 220(4595): p. 423-425.

[27] Poordad, F., et al., Boceprevir for untreated chronic HCV genotype 1 infection. New England Journal of Medicine, 2011. 364(13): p. 1195-1206.

[28] Jacobson, I.M., et al., Telaprevir for previously untreated chronic hepatitis C virus infection. New England Journal of Medicine, 2011. 364(25): p. 2405-2416.

[29] Jacobson, I.M., et al., Sofosbuvir for hepatitis C genotype 2 or 3 in patients without treatment options. New England journal of medicine, 2013. 368(20): p. 1867-1877.

[30] Lawitz, E., et al., Sofosbuvir for previously untreated chronic hepatitis C infection. New England Journal of Medicine, 2013. 368(20): p. 1878-1887.

[31] Zeuzem, S., et al., Sofosbuvir and ribavirin in HCV genotypes 2 and 3. New England Journal of Medicine, 2014. 370(21): p. 19932001.

[32] Eisenberg, D.M., et al., Trends in alternative medicine use in the United States, 1990-1997: results of a follow-up national survey. Jama, 1998. 280(18): p. 1569-1575.

[33] Vickers, A., Recent advances: complementary medicine. BMJ: British Medical Journal, 2000. 321(7262): p. 683.

[34] Liu, J., et al., Medicinal herbs for hepatitis C virus infection: a Cochrane hepatobiliary systematic review of randomized trials. The American journal of gastroenterology, 2003. 98(3): p. 538-544.

[35] Gupta, N. and J. Lewis, Review article: The use of potentially hepatotoxic drugs in patients with liver disease. Alimentary pharmacology \& therapeutics, 2008. 28(9): p. 1021-1041.

[36] Worwood, M., Indicators of the iron status of populations: ferritin. WHO, CDC. Assessing the iron status of populations, 2nd ed. Geneva, World Health Organization, 2007: p. 35-74.

[37] Thorburn, D., et al., The role of iron and haemochromatosis gene mutations in the progression of liver disease in chronic hepatitis C. Gut, 2002. 50(2): p. 248-252.

[38] Fabris, C., et al., Serum iron indices as a measure of iron deposits in chronic hepatitis C. Clinica chimica acta, 2001. 304(1): p. 4955.

[39] ERSOY, O. and Y. BÜYÜKAfiIK, Serum iron parameters in cirrhosis and chronic hepatitis: detailed description. Turk J Gastroenterol, 2011. 22(6): p. 606-611.

[40] Barut, S., Ö. Günal, and U. Erkorkmaz, Serum ferritin levels in chronic hepatitis C patients during antiviral therapy and prediction of treatment response. Scandinavian journal of infectious diseases, 2012. 44(10): p. 761-765. 
[41] Ryan, J.D., et al., Pegylated interferon- $\alpha$ induced hypoferremia is associated with the immediate response to treatment in hepatitis C. Hepatology, 2012. 56(2): p. 492-500.

[42] Eijk, V., Regulation of iron metabolism in the acute-phase response: interferon $\gamma$ and tumour necrosis factor $\alpha$ induce hypoferraemia, ferritin production and a decrease in circulating transferrin receptors in cancer patients. European journal of clinical investigation, 1998. 28(7): p. 520-527.

[43] Pockros, P.J., Interferon-free hepatitis C therapy. Drugs, 2012. 72(14): p. 1825-1831.

[44] De Franceschi, L., et al., Hemolytic anemia induced by ribavirin therapy in patients with chronic hepatitis $\mathrm{C}$ virus infection: role of membrane oxidative damage. Hepatology, 2000. 31(4): p. 997-1004.

[45] Azzam, H., et al., Natural products and chronic hepatitis C virus. Liver International, 2007. 27(1): p. 17-25. 